\title{
Influences of Guanzi Economic Thought on the Construction of Current Management Accounting System Jin Guangmei
}

\author{
Zaozhuang Institute of Economics and Management, Zaozhuang College, 277160 China \\ Email: 27306383@qq.com
}

Tel: 13906321321

Keywords: Guanzi thought; Management accounting system; Reference

\begin{abstract}
China's accounting work has entered a period of diversified development, the focus of work has turned to management accounting. As a very famous economic management scientist in Chinese history, Guan Zhong put forward a series of economic ideas with excellent vision. Through this paper, "GuanZi" is a kind content of center of responsibility and fine accounting, the cost and benefit of the management accounting system and performance incentive mechanism other aspects of the interpretation, providing some important reference and inspiration to the current management accounting system.
\end{abstract}

\section{Introduction}

So-called management accounting can be interpreted as "corporate financial management of internal control accounting", from the basic accounting of the original data to confirm, measurement, record, report, so that financial information users can occur in the economic business planning, control And decision making. Management accounting is the inherent product of the development of modern enterprise in our country, the development of market economy and the upgrading of enterprise transformation and upgrading, so that the function of management accounting are increasingly reflected. The construction of the management accounting system can provide decision-making information such as forecasting, control and evaluation, optimizing the cost structure, improving the production and operation process, and emphasizing the fine accounting of the center of responsibility. Through continuous optimization of business processes to expand the extension, improve and stabilize the industry supply chain effect. How to establish a management accounting system with clear responsibilities, reasonable cost and effective performance incentive is a long way to go.

Then this early in China's Spring and Autumn period by the "by the words", "foreign words", "words", "phrase", "district words", "miscellaneous articles", " Guanzi solution", " Guanzi weight" Constitute the "Guanzi " a book, as the cultural treasures of the history of the Chinese nation, embodies the wisdom of many human management and economic thinking, the current reform on the management accounting system will be how the impact and inspiration, how do we learn from it.The essence of accounting culture construction, especially for the development of management accounting system theory research, hope that the economic thinking of the Guanzi can provide further guidance for the further study of management accounting system. This paper will elaborate from the three aspects of the management center of the accounting system, the cost income and the performance incentive mechanism.

\section{The Guanzi "on the workers, review the current affairs" and the center of responsibility and fine accounting in the management accounting system}

《Guanzi legislation"》said: "repair fire constitution, building bridge, Lin Tau, plot grass, so that the people in the palace with the salary of the plot, Yu Shi things also. In the village, depending on the palace, view tree art, Jane six animals, to Jun repair Yan, rego to the village, the division of the division of things Also on the hundred workers, the examination of the current affairs, the demeanor 
of the bitter, on the benefit, the supervision of a five townships, to Jun repair Yan, so engraved, dare not made in the township, the division of things. "In this book how to assess the specific work of a variety of craftsmen, according to different sections of the review of their respective operating projects, to assess their respective product quality level. Such as the security of their "division of the matter" pay attention to promote the product refined and perfect, the management of five townships, on time and reasonable coordination and other basic duties. So for the current, for each accounting work assessment, not just at different times to review the specific accounting tasks, but also to observe the different positions of work attitude and efficiency, all-round clear responsibilities and objectives of coordination Comprehensive accounting work arrangements, unified deployment of management, management accounting system is the primary basis of the work.

The so-called departmental authority center is in the unit under the overall management objectives, based on people, relatively independent of a certain management power and the corresponding economic responsibility of an internal unit. Therefore, the objectives and tasks of the accounting authority center will be the composition of the overall objectives of the unit, a number of accounting center of responsibility to complete their own goals, and promote the overall responsibility of the unit to achieve the ultimate goal. Reasonable authority within the scope of an independent accounting authority is effective and feasible, to some extent only to give all organizations a certain mandate to better play to create the enthusiasm and subjectivity of the work, fully centralized accounting responsibility model is not actually Conducive to the coordination between the various positions, if the units of the various departments and departments between the powers and responsibilities are not clear, but for a job is mutual responsibility, exposing the unit management accounting system, both management accounting relationship and the two deal with the right, integrate development is indispensable. In fact, only the combination of the future development goals and revenue and expenditure situation, and then set the various rights center unit objectives, can be specific to develop a corresponding financial management more refined and precise accounting program to support the organization Internal daily refinement of business decision-making management needs to promote the final and overall unit of long-term development.

\section{The Guanzi "trial measure, frugal" and on the cost and benefit of the Management Accounting System}

《Guanzi seven primes and seven ministers》said: "Therefore, there are six civil affairs of the four ban. Six servants who also for a section, two for sage, three for the program, four for all, five days, six Should be. " Guanzi "a book clearly pointed out that the government must have six policy ban, section is the first six. So how does this section of the Guanzi understand? "Guanzi by horse," said, "the extravagance of the precious, the expensive is cheap, so the goods do not know the goods do not know the amount of" Here for the "injury" understanding is that the waste is not useful, and "do not know" is excessive control consumption. In the "Guanzi of eight view" and further explain the "trial measures, section clothes, frugality, forbidden Thai, for the country also urgent." So that the economic thinking of the Guanzi for the "section" "thrifty" interpretation, focus in the "measure", in fact, close to the now mentioned "standardization and institutionalization" scale management, whether it is strictly control any cost, or reasonable range of expenses to reduce costs, how to better achieve the expenditure and cost Relative balance of purpose. "The Guanzi is the same as the cost of the capital of two times, then no sale of his son (Four times); things five of its own, then far and near pass, dead to possession (to achieve the three Five times. "Clearly express the difference between cost and profit.

The starting point for the use of management accounting tools in today's enterprises is often considered from both cost and benefit. Often applied to the management accounting tools, such as production accounting, cost analysis, standard cost method, cost-benefit analysis, target cost, unified cost accounting, management risk accounting and so on. Use the effect of intensity is still stuck in the surface of a simple analysis: for example, due to the current production and operation costs are too high, but the market income is too low, the natural business efficiency is not good. 
There are many enterprises in the production process of the process is lengthy, many processes are redundant cumbersome, will increase the unnecessary costs, effective communication between functional departments, unreasonable performance evaluation and unfair distribution, a series of problems will cause staff work enthusiasm poor, slow production efficiency, production and management efficiency is not improved, and ultimately lead to enterprise development stagnant, and even face collapse. In the case of the return on investment in the cost-benefit view, it is based on the previous year's income measurement table, which is based on the forecast of the cost of the specific project, the income and the cash flow, and then the income, cost and expense of the specific project. We will come to the analysis: the cost of the composition of the general, as a standardized basis for calculation; calculated based on the conversion rate of static return on investment and dynamic investment return period, but also for different projects between the operating results to provide real data support.

So how to change this state, to achieve the benign relationship between cost and benefit, choose their own business management accounting tools, objectives clearly improve the actual problems of enterprises, access to stable and long-term development. To combine costs, risks, resources, plans, benefits, and so on the whole process of a number of content, not a single management accounting tools, the need for a variety of management accounting tools in different dimensions, vertical and horizontal use. But also to consider whether the establishment of modern enterprise system, economic business, financial accounting of the use of large data, as well as a clear long-term strategic objectives of the enterprise is to establish a prerequisite for the management of accounting applications. How to further make the cost of accounting fees and management accounting approach consistent, better optimize the accounting management process, not only play a variety of financial information, the basic accounting "back to see" function, you can also make better use of large data to play the management of accounting forecasting, control and other business activities to monitor the "look ahead" function.

\section{Guanzi "executive first, give gold" and management accounting system performance incentive mechanism}

《Guanzi of light and heavy》 said: "the age of the rent of forty-two thousand dollars, please a prime priest." "Who can trap broken people, thanks to the hundred gold." "Thousands of people, "The soldiers of the cross, who can die in the elderly, thanks to the hundred gold." Asked: "Geometric death of the people also?" Guanzi said: "thousands of people long." " Thousands of people long, the minister can get. "Given the hundred gold. "Who can listen to the meaning of the flag, and the executive will be the first, given the daughter." Words can be a thousand people, thanks to the hundred of gold. The rest of the words can be outside the beheaded, given the people of ten gold. "Do not suffer, and make the name of the outside, the township for its private, the family for his wife in other country, if so, then the priest will be famous for the moral, no meaning of the North. The destruction of its army, and its place, "Banner flag is not wide, not known, and Lai people big escape. It was broken its army, and its place, and prisoners will be. It is not listed and sealed, not out of gold and reward, breaking the army, and its land, captured its king. This element of the reward also analysis: Who can trap against the enemy, reward 100 pounds of gold; break more than a thousand troops, reward a hundred pounds of gold. If you can capture the enemy's death, reward gold jack; capture a thousand enemy soldiers directly reward a hundred pounds of gold. Able to kill the enemy, reward no one ten pounds of gold. One morning "prey", forty thousand two kilograms of gold are light. Rewards are reasonable to fight outside the enemy's soldiers can glory village, the parents have light, there are good wife, so motivated so generous they will certainly be able to kill the enemy newspaper country, no cowardice, and if not fighting on the front, how good back To the village to accept such a generous treatment. This is the positive policy of Guanzhong's pre-reward, which reflects how Guanzhong's rewards and punishments through the establishment of a sound incentive mechanism. This kind of economic management thought has the same meaning and influence to the present enterprise's performance system. 
Theory and practice proved that as one of the management accounting application methods to establish a sound performance incentive mechanism can improve the efficiency and improve the industrial efficiency, in order to achieve the optimal mode of resources. So how to achieve performance incentive management? Including the following aspects of the establishment of different performance incentive goals, strictly in the practice of running monitoring records, the implementation of a truly effective performance appraisal and other links. First of all, from the concept of the effective implementation of the performance incentive management philosophy, in the management of accounting system in the implementation of all aspects of the implementation of performance incentive mechanism management, the same can drive the overall management system mechanism to enhance the responsibility of the various departments and responsibilities, with scientific fine management objectives. In practice, the design of the evaluation index system for performance incentive is especially critical, including both financial data and non-financial data, and multi-dimensional cross-examination. Common financial indicators are usually capital budget execution rate, asset-liability ratio, quick ratio, staff expenditure ratio, cost profit ratio, total assets growth rate; non-financial data performance indicators include the unit as a whole, customer satisfaction management, personnel management, staff training, innovation, social responsibility, market share and so on.

The current large data environment, many companies use large data information for performance incentive mechanism management, but also with the management of accounting tools. Such as the use of the enterprise balanced scorecard management to manage the performance of employees, so as to ensure the fairness of the overall performance incentive mechanism. The enterprise performance incentive evaluation indicators, fine management, customer relationship management and other business management objectives are combined, not only beneficial to employees, the responsibility of the department and the entire organization of performance appraisal, but also more effective to achieve the transformation of business management development of. In addition, enterprises should continue to improve the performance of innovation and performance evaluation of incentives, regulate this important indicator system, there is no measure no management, so to ensure that the measurement of indicators of rationality and scientific, so that the enterprise management accounting system to achieve a certain. The height of a more robust protection and support. The enterprise's performance incentive mechanism and the staff assessment work into the enterprise management accounting system construction, attention to business talent, to provide career development channels to match the reasonable salary, the use of management accounting system to establish the application to retain talent, So that employees achieve their own professional value, while enterprises will create greater economic benefits.

\section{References}

[1] Zhu Qinghai.Optical accounting application based on internal control system [J]. Finance and Accounting, 2014

[2] Chen Hongfen. How to strengthen the internal control of corporate accounting [J]. China collective Economy, 2015

[3] Pan Li Ping. From the perspective of management accounting on the implementation and improvement of corporate internal control[J]. Enterprise Reform and Management, 2015

[4] Chen Wei, Hou Xiaojiao. Based on large data environment analysis on the Influencing Factors of Trust in management accounting information system [J]. International Business Accounting, 2015 ,

[5] Zhang Rong. The four modules of enterprise management accounting system construction[J]. Finance and Accounting, 2015

[6] Zhao Ying, Chen Yuandong. China's management accounting research methods of choice and development resistance[J]. Financial accounting, 2016 
[7] Ministry of Finance. "On the comprehensive promotion of the management of accounting system construction guidance" (Accounting [2014] No. 27). 